\title{
Outcome in women with previous caesarean section in a secondary care hospital in rural South India
}

\author{
Anuradha Dhanasekaran ${ }^{1}$, Anne George Cherian ${ }^{2 *}$, Aabidha Parveen ${ }^{1}$, Paul Emmanuel ${ }^{1}$
}

\author{
${ }^{1}$ Department of Obstetrics and Gynaecology, Christian Fellowship Hospital, Oddanchatram, Tamil Nadu, India \\ ${ }^{2}$ Department of Community Medicine, Christian Medical College, Vellore, Tamil Nadu, India
}

Received: 11 August 2016

Accepted: 06 September 2016

\section{*Correspondence:}

Dr. Anne George Cherian,

E-mail: annegc97@yahoo.co.in

Copyright: (C) the author(s), publisher and licensee Medip Academy. This is an open-access article distributed under the terms of the Creative Commons Attribution Non-Commercial License, which permits unrestricted non-commercial use, distribution, and reproduction in any medium, provided the original work is properly cited.

\begin{abstract}
Background: Caesarean section has become increasingly the common method of delivery. From 1980 to 2001 the rate in UK has increased from $9 \%$ to $21 \%$ of all births. The aim of the study was to find out the outcome of delivery in women with previous cesarean section, the mode of delivery, maternal and fetal outcome of labour and various factors which influence the mode of delivery.

Methods: 150 women with one previous caesarean section who attended the antenatal clinic and fit the inclusion criteria were enrolled in the study.

Results: Success rate of VBAC was $30.5 \%$ among those included in trial of labour after caesarean section (TOLAC). $60.7 \%$ of the enrolled women underwent elective repeat caesarean section of which $54.9 \%$ were at the patients' request. Favorable Bishop's score $(\mathrm{p}=0.0002)$ and previous cesarean section for breech $(\mathrm{p}=0.191)$ are positively associated with VBAC. Incidence of maternal complications in the study was $10.67 \%$ and $2.5 \%$ babies had an Apgar $<7$ at 5 minutes. There was no maternal or neonatal mortality.

Conclusions: The VBAC rate in the study is $30.5 \%$ in carefully selected patients for trial of scar with the existing litigation pressure. TOLAC can be judiciously implemented in carefully chosen patients even in rural health setting equipped with required facilities. Patient's participation in the decision making has brought down the VBAC rate which is reflected by the increased repeat elective cesarean section done at patients' request (54.9\%). Factors such as prior vaginal delivery, favorability of the cervix, indication of previous cesarean section, onset of labour and birth weight are highly significant in deciding the success of VBAC and can be used to improve VBAC rates in practice.
\end{abstract}

Keywords: Previous caesarean section, TOLAC, Secondary hospital, Outcomes

\section{INTRODUCTION}

Caesarean section has become increasingly the common method of delivery. From 1980 to 2001 the rate in UK has increased from $9 \%$ to $21 \%$ of all births and was most recently reported as $24.8 \%$. $^{1,2}$ A similar increase is noted in USA and Australia. India has not been far behind.

A five year audit in a large teaching hospital in Kolkata revealed a caesarean section rate of $49.9 \%$, while a hospital in Chennai showed a rate of $32.6 \%$ with rates in the private sector at $47 \% .{ }^{3,4}$ An evaluation of caesarean sections by the American College of Obstetricians and Gynecologists reported that first time mothers, with term singleton cephalic pregnancies and women with a previous caesarean section account for the greatest increase in rates of caesarean section and much of the variation between institutions.

Higher rates of caesarean delivery are associated with increased maternal and neonatal morbidity. ${ }^{5}$ Rising rates of caesarean deliveries are assumed to have been driven by obstetricians, reflecting medico legal concerns about vaginal birth after previous caesarean section (VBAC), vaginal breech delivery and fetal distress in labour. There is also increased emphasis in involvement of patients in the decision making. Repeat caesarean sections account 
for the major share of the present day indications for caesarean sections.

In India, the repeat caesarean section rate was $29 \%$ in 2002 and has remained more or less the same. In United States, the VBAC rates had risen from $6.6 \%$ in 1985 to $28 \%$ in 1996 . However, the VBAC rates have fallen from $24 \%$ in 1999 to $8.5 \%$ in 2006 because of some uterine ruptures and the litigation associated with it. ${ }^{6,7}$

VBAC is a reasonable and safe choice for the majority of women with prior caesarean. Moreover, there is emerging evidence of serious harm relating to multiple caesareans. Relatively, unexamined contextual factors such as medical liability, economics, hospital structure, and staffing may need to be addressed to prioritize VBAC services. There is still no evidence to inform patients, clinicians, or policymakers about the outcomes of intended route of delivery because the evidence is based largely on the actual route of delivery. ${ }^{8}$ However, an apparent increase in the frequency of uterine rupture and concern about maternal and perinatal morbidity has challenged the safety and appropriateness of vaginal birth after caesarean delivery. ${ }^{9}$

These issues, along with medico legal pressures and the introduction of more stringent criteria for a trial of labor after caesarean delivery, have led to a substantial decline in the rate of vaginal birth after caesarean section. ${ }^{10}$

The aim of this study was to find out the outcome of delivery in women with previous LSCS in a secondary level hospital in rural Tamil Nadu in regard to mode of delivery and maternal and fetal outcome. Also to access the factors which influence the mode of delivery.

\section{METHODS}

This was a prospective, analytical study carried out in the Department of Obstetrics and Gynaecology of Christian Fellowship Hospital, Oddanchatram, Tamil Nadu, India. This is a secondary level hospital which caters mainly to agricultural and rural population and has sufficient staff for monitoring those in labours as well provisions for anesthesia and emergency surgeries if indicated.

With the prevalence of previous caesarean section in the hospital at $11 \%$, a sample size of 150 was calculated and all women with one previous LSCS who were admitted after 28 weeks of gestation were included in this study. Those with more than one previous LSCS, prior inverted $\mathrm{T}$ or unknown incision or any other uterine surgeries were excluded from the study.

Once a patient was enrolled in the study, informed consent was taken. On admission her previous records were verified, contraindications for VBAC were ruled out ACOG criteria applied and Bishops score of cervix assessed. Based on previous records, present antenatal records and Bishops score, decision for trial of labour after caesarean (TOLAC) or elective repeat caesarean section (ERCS) was taken by the treating physician in consultation with the patient.

If the patient wanted a repeat LSCS, a written consent was taken and the course of events intra op and post op were noted on the patients' proforma. If the patient consented to TOLAC, ripening of cervix was done if needed with a stretch and sweep and labour augmented with oxytocin. Throughout labour, the fetal heart rate monitoring was performed using the cardiotocography machine. The labour progress was plotted on a partogram and per vaginal examination was done every 4 hours. If the progress was adequate then she allowed continuing in labour. In case of an inadequate progress or any signs of fetal distress she was immediately posted for Emergency cesarean section.

\section{RESULTS}

Of the 150 patients with Previous LSCS, 59 were carefully selected for trial of labour. Of these only 18 $(30.5 \%)$ had successful VBAC and $41(69.5 \%)$ had a repeat LSCS (Table 1).

Table 1: Management of subjects.

\begin{tabular}{|l|l|l|}
\hline Route of delivery & Total patients & Percentage \\
\hline Elective LSCS & 91 & 60.7 \\
\hline Trial of labour & 59 & 39.3 \\
\hline (i) Successful VBAC & 18 & 30.5 \\
\hline (ii) Repeat LSCS & 41 & 69.5 \\
\hline
\end{tabular}

Of the 18 who had a successful VBAC, 6 delivered spontaneously and 12 were assisted either by vacuum or forceps. 41 patients in the study among those opting for TOLAC ended up with repeat LSCS (Table 2).

Table 2: Indications for repeat LSCS.

\begin{tabular}{|lll|}
\hline Indications for repeat & $\begin{array}{l}\text { Total } \\
\text { patients }\end{array}$ & Percentage \\
\hline Failed induction & 3 & 7.3 \\
\hline Fetal distress & 24 & 58.5 \\
\hline Suspected CPD & 1 & 2.5 \\
\hline Non progress of labour & 13 & 31.7 \\
\hline
\end{tabular}

Out of 150 patients in the study, $91(60.7 \%)$ had repeat elective LSCS, of which majority of the caesareans were done for previous caesarean section (PCS) not willing for $\operatorname{VBAC}(54.9 \%)$ and CPD (17.5\%) (Table 3)

Factors affecting TOLAC were also observed in this study.

Out of 150 women only $11(7.3 \%)$ have had a prior vaginal delivery. Out of the 11 women who had a prior vaginal delivery before the cesarean section, 6 had a repeat elective caesarean section, 2 had a successful 
VBAC, 3 had a repeat emergency caesarean section. Presence of a vaginal delivery before caesarean section is not statistically associated with the mode of delivery ( $p$ value of 0.730 ).

Table 3: Indications for elective LSCS ( $n=91)$.

\begin{tabular}{|lll|}
\hline Indications & $\begin{array}{l}\text { Number } \\
\text { of patients }\end{array}$ & Percentage \\
\hline Previous caesarean section & 50 & 54.9 \\
\hline Malpresentation & 5 & 5.5 \\
\hline Placenta previa & 2 & 2.2 \\
\hline $\begin{array}{l}\text { CPD/disproportion/ } \\
\text { macrosomia }\end{array}$ & 16 & 17.5 \\
\hline Severe preeclampsia & 6 & 6.6 \\
\hline BOH & 3 & 3.3 \\
\hline Others & 6 & 6.6 \\
\hline $\begin{array}{l}\text { Severe IUGR with } \\
\text { oligohydramnios }\end{array}$ & 3 & 3.3 \\
\hline
\end{tabular}

On admission, in 59 women chosen for TOLAC, 38 (64.5\%) had a Bishops score of <6, 21 (35.5\%) had a score of $\geq 6$. Bishop's score $\geq 6$ was significantly associated with successful VBAC with a $p$ value of $<0.0002$.

On correlating the indication for previous caesarean section with the present mode of delivery using $\mathrm{p}$ value, odds ratio (OR) with $95 \%$ confidence interval (CI), women who had previous caesarean section for malpresentation (p-0.191, OR-2.85, CI-0.81-10.06), severe pre-eclampsia (p-0.298, OR-2.23, CI- 0.43-11.68), precious pregnancy (p-0.300, OR-7.71, CI- 0.46-128.9) are positively associated with successful VBAC with a low $p$ value. Women who had a previous caesarean section for fetal distress (p-0.060, OR- 0.23, CI-0.041.03) are significantly associated with repeat caesarean section (Table 4).

Table 4: Women significantly associated with repeat caesarean section.

\begin{tabular}{|c|c|c|c|c|c|c|}
\hline \multirow[b]{2}{*}{ Indication (n) } & \multicolumn{3}{|c|}{ Mode of delivery } & \multirow[b]{2}{*}{ P-value } & \multirow[b]{2}{*}{$\begin{array}{l}\text { Odds } \\
\text { ratio }\end{array}$} & \multirow[b]{2}{*}{$95 \% \mathrm{CI}$} \\
\hline & $\begin{array}{l}\text { El LSCS } \\
(\mathrm{n}=91)\end{array}$ & $\begin{array}{l}\text { Successful } \\
\text { VBAC }(n=18)\end{array}$ & $\begin{array}{l}\text { Repeat LSCS } \\
(\mathrm{n}=41)\end{array}$ & & & \\
\hline Malpresentation (16) & $9(9.9 \%)$ & $4(22.2 \%)$ & $3(7.3 \%)$ & 0.191 & 2.85 & $0.81-10.06$ \\
\hline Severe preeclampsia (9) & $6(6.6 \%)$ & $2(11.1 \%)$ & $1(2.4 \%)$ & 0.298 & 2.23 & $0.43-11.68$ \\
\hline Placenta praevia $(2)$ & $0(0 \%)$ & $0(0 \%)$ & $2(4.9 \%)$ & 0.153 & - & - \\
\hline Precious pregnancy (2) & $1(1.1 \%)$ & $1(5.6 \%)$ & $0(0 \%)$ & 0.300 & 7.71 & $0.46-128.9$ \\
\hline Failed induction (30) & $17(18.7 \%)$ & $5(27.8 \%)$ & $8(19.5 \%)$ & 0.664 & 1.65 & $0.54-5.04$ \\
\hline Failed vacuum (3) & $3(3.3 \%)$ & $0(0 \%)$ & $0(0 \%)$ & 0.695 & - & - \\
\hline Fetal distress (49) & $30(33 \%)$ & $2(11.1 \%)$ & $17(41.5 \%)$ & 0.060 & 0.23 & $0.04-1.03$ \\
\hline CPD (16) & $13(14.3 \%)$ & $2(11.1 \%)$ & $1(2.4 \%)$ & 0.100 & 0.49 & $0.06-4.01$ \\
\hline Others (15) & $10(11 \%)$ & $1(5.6 \%)$ & $4(9.8 \%)$ & 0.925 & 0.49 & $0.06-4.01$ \\
\hline Not specified (8) & $2(2.2 \%)$ & $1(5.6 \%)$ & $5(12.2 \%)$ & 0.041 & 1.05 & $0.12-9.06$ \\
\hline
\end{tabular}

Table 5: Correlation of induction of labour with the outcome of TOL $(n=59)$.

\begin{tabular}{|lll|}
\hline Successful VBAC & $\begin{array}{l}\text { Induction } \\
\text { of labour }\end{array}$ & $\begin{array}{l}\text { Spontaneous } \\
\text { labour }\end{array}$ \\
\hline CS following TOL & $17(68 \%)$ & $10(29.4 \%)$ \\
\hline Total & $25(100.0 \%)$ & $24(70.6 \%)$ \\
\hline Inference & $\begin{array}{l}\text { Onset of labour is not } \\
\text { statistically associated with } \\
\text { mode of delivery with } \mathrm{p}=0.964\end{array}$ \\
\hline
\end{tabular}

Out of the 59 selected for a trial of labour, 25 women had induced labour, of which $8(32 \%)$ had a successful VBAC and 17 (68\%) had a repeat emergency caesarean section. 34 women presented with a spontaneous onset of labour, of which 10 (29.4\%) had a successful VBAC and $24(70.6 \%)$ had a repeat emergency caesarean section.
The onset of labour was not statistically associated with the outcome of trial of labour with a $\mathrm{p}$ value of 0.964 (Table 5).

There were 12 babies with a birth weight of $\geq 3.5 \mathrm{~kg}$. Out of which 10 babies with birth weight of $3.5-4 \mathrm{~kg}, 8$ delivered by elective LSCS and 2 delivered by emergency LSCS following failed TOL. There were only 2 babies $>4 \mathrm{~kg}$ delivered by elective LSCS. High birth weight is statistically associated with a repeat elective LSCS with a $p$ value of 0.304 .

Out of the 150 deliveries, 6 babies had an Apgar of $<7$ at one minute, of which $1(1.1 \%)$ was born by elective LSCS, $2(11.1 \%)$ born vaginally and $3(7.5 \%)$ born by an emergency LSCS. Only $1(2.5 \%)$ baby had an Apgar of $<7$ at five minutes, delivered by an emergency LSCS. The incidence of maternal complications in the study was $10.67 \%$. $4.39 \%$ had PPH in the elective LSCS and $6.77 \%$ 
had PPH in TOL. $1.10 \%$ had puerperal infection in the elective LSCS group. The other maternal complications in the women who had a trial of labour are scar dehiscence $(6.77 \%)$, scar dehiscence with bladder involvement $(3.39 \%)$ and $3^{\text {rd }}$ degree perineal tear $(1.69 \%)$

\section{DISCUSSION}

Each delivery method has its advantages and disadvantages. It is ultimately the responsibility of the obstetrician to ensure that the delivery plan is appropriate for each individual case. The stimulus for interest in vaginal birth after cesarean section was probably the progressive rise in the cesarean section rate.

The increased morbidity and mortality associated with cesarean section as compared to vaginal delivery is clearly borne out by the literature. ${ }^{11} \mathrm{Th}$

is fact together with the lower reported incidence of uterine rupture and consequent maternal and fetal compromise strongly argues for the trial of labour in carefully selected patients with previous cesarean section. $^{12}$

The vaginal delivery rate in this study is $30.5 \%$ in carefully selected patients for a trial of labour. Bashir et al have reported a $41.53 \%$ of vaginal delivery in women with previous one LSCS. Though The VBAC rate in the study is only $30.5 \%$ when compared to the expected rate of $60-80 \%$, still it is comparable to a VBAC rate of $32.4 \%$ by Chhabra et al in a rural health centre in Central India. $^{13}$

The study had only $7.3 \%$ of women who had a prior vaginal delivery, of which $11.1 \%$ had a successful VBAC which couldn't be statistically associated with the mode of delivery $(p=0.730)$. Other studies show that presence of a prior vaginal delivery is positively associated with a successful VBAC. Mock et al show that a successful TOL correlates positively with the number of prior vaginal deliveries. ${ }^{14}$ Bedoya et al demonstrated that women with previous vaginal delivery had a higher rate of vaginal delivery after a TOL $(95.24 \%)$ than those without previous vaginal delivery $(82.95 \%) .{ }^{15}$ This is because the number of women who had a prior vaginal delivery in the study was very less to obtain a positive association with successful VBAC.

This study shows a statistically significant correlation between favorable Bishop's score and the success of TOL with a $\mathrm{p}$ value of 0.0002 . Madaan et al report a success rate of TOL to be $53.6 \%$ with a favorable Bishop's score $(\mathrm{p}=0.000){ }^{16}$

On correlating the indications for which primary caesarean section was done with the present mode of delivery, cesarean sections for malpresentation, i.e, breech $(\mathrm{p}=0.191)$, severe pre-ecclampsia $(\mathrm{p}=0.298)$ and precious pregnancy $(\mathrm{p}=0.030)$ were positively associated with successful VBAC. Madaan et al showed a high chance of vaginal delivery $(67.1 \%)$ in those who had breech as an indication of previous CS. ${ }^{16}$ Chhabra et al reports a $36.6 \%$ and $68.7 \%$ of successful vaginal delivery for whom a primary CS was done for malpresentation and fetal distress respectively. ${ }^{13}$

In the study eight out of the ten babies weighing $3.5-4 \mathrm{~kg}$ and 2 babies of $>4 \mathrm{~kg}$ weight had a repeat elective LSCS. High birth weight is significantly associated with a repeat CS $(p=0.304)$. Hin et al shows that a logistic regression analysis showed that a birth weight of $<2500 \mathrm{~g}$ or $>3500 \mathrm{~g}$ has most significant association with emergency LSCS rate. ${ }^{17}$ The incidence of maternal complications was $10.67 \%$. $5.33 \%(8 / 150)$ had post-partum hemorrhage (PPH) of which $6.77 \%(4 / 59)$ in TOL and $4.39 \%(4 / 91)$ in patients with elective cesarean section. $6.77 \%(4 / 59)$ had scar dehiscence, $3.39 \%$ (2/59) had scar dehiscence with bladder involvement.

From this study we conclude that VBAC rate is $30.5 \%$ in carefully selected patients for trial of labour in the presence of resource constraints and with existing litigation pressure. As this rate is comparable to other studies, TOL can be judiciously implemented in carefully chosen patients even in rural health setting equipped with required facilities.

Patient's participation in the decision making has brought down the VBAC rate which is reflected by the increased repeat elective cesarean section done for a previous cesarean section $(54.9 \%)$.

Factors such as prior vaginal delivery, favorability of the cervix, indication of previous cesarean section, onset of labour and birth weight are highly significant in deciding the success of VBAC, which if properly implemented, can be used to greatly improve VBAC rates in practice.

\section{ACKNOWLEDGEMENTS}

Authors would like to acknowledge the efforts of the staff of the Department of Obstetrics and Gynaecology of Christian Fellowship Hospital, Oddanchatram, India.

Funding: No funding sources

Conflict of interest: None declared

Ethical approval: The study was approved by the Institutional Ethics Committee

\section{REFERENCES}

1. 624 RCOG NSCS Audit - nscs_audit.pdf. Available from: https: //www.rcog.org.uk /globalasset s/documents/guidelines/researchaudit/nscs_audit.pdf. Accessed on 12 January 2016.

2. Health and social care information centre 1 trevelyan square. 2012. Available at: http: //www.hscic.gov.uk /article/2021/Website-Search? productid $=116 \& q=$ 
CAESAREAN+SECTION+2014\&sort=Relevance \& size $=10 \&$ page $=1 \&$ area $=$ both $\#$ top. Accessed on 3 January 2016.

3. Pahari K, Ghosh A. Study of pregnancy outcome over a period of five years in a postgraduate institute of west Bengal. J Indian Med Assoc. 1997;95(6):172-4.

4. Sreevidya S, Sathiyasekaran BWC. High caesarean rates in Madras (India): a population-based cross sectional study. BJOG Int J Obstet Gynaecol. 2003;110(2):106-11.

5. Villar J, Valladares E, Wojdyla D, Zavaleta N, Carroli G, Velazco A, et al. Caesarean delivery rates and pregnancy outcomes: the 2005 WHO global survey on maternal and perinatal health in Latin America. Lancet. 2006;367(9525):1819-29.

6. Kambo I, Bedi N, Dhillon BS, Saxena NC. A critical appraisal of cesarean section rates at teaching hospitals in India. Int J Gynaecol Obstet Off Organ Int Fed Gynaecol Obstet. 2002;79(2):151-8.

7. Smith A. New guidelines seek to cut rate of repeat cesarean sections. Available at http://blog.syracuse.com/cny/2010/07/new_guideline s_seek_to_cut_rate_of_repeat_cesarean_sections.htm 1. Accessed on 20 January 2015.

8. Guise JM, Eden K, Emeis C, Denman MA, Marshall $\mathrm{N}, \mathrm{Fu} \mathrm{RR}$, et al. Vaginal birth after cesarean: new insights. Evid Report Technology Assess. 2010;(191):1-397.

9. Sachs BP, Kobelin C, Castro MA, Frigoletto F. The risks of lowering the cesarean-delivery rate. $\mathrm{N}$ Engl J Med. 1999;340(1):54-7.

10. Martin JA, Hamilton BE, Ventura SJ, Menacker F, Park MM, Sutton PD. Births: final data for 2001.
Natl Vital Stat Rep Cent Dis Control Prev Natl Cent Health Stat Natl Vital Stat Syst. 2002;51(2):1-102.

11. Flamm BL. Vaginal birth after caesarean (VBAC). Best Pract Res Clin Obstet Gynaecol. 2001;15(1):8192.

12. Weinstein D, Benshushan A, Tanos V, Zilberstein R, Rojansky N. Predictive score for vaginal birth after cesarean section. Am J Obstet Gynecol. 1996;174(1):192-8.

13. Vaginal birth after one previous lower segment caesarean section. Available at: http:// www.jkscience.org/archive/volume134/Vaginal\%20 Birth\%20After\%20One\%20Previous\%20Lower\%20 Segment\%20Caesarean\%20Section.pdf. Accessed on 2 January 2016.

14. Mock CN, Visser L, Elkins TE, Wilson JB. Vaginal delivery after previous cesarean section in a rural West African hospital. Int J Gynaecol Obstet Off Organ Int Fed Gynaecol Obstet. 1991;36(3):187-93.

15. Bedoya C, Bartha JL, Rodriguez I, Fontan I, Bedoya JM, Ramos SJ. A trial of labor after cesarean section in patients with or without a prior vaginal delivery. Int J Gynaecol Obstet Off Organ Int Fed Gynaecol Obstet. 1992;39(4):285-9.

16. Madaan M, Agrawal S, Nigam A, Aggarwal R, Trivedi SS. Trial of labour after previous caesarean section: the predictive factors affecting outcome. J Obstet Gynaecol J Inst Obstet Gynaecol. 2011;31(3):224-8.

17. Hin LY, Khairuddin Y, Ng KB. The predictive value of extremes of birth weight, mother's height and ethnic origin on the likelihood of emergency caesarean section. Asia-Ocean J Obstet Gynaecol. 1994;20(4):389-94.

Cite this article as: Dhanasekaran A, Cherian AG, Parveen A, Emmanuel P. Outcome in women with previous caesarean section in a secondary care hospital in rural South India. Int J Reprod Contracept Obstet Gynecol 2016;5:3532-6. 